\title{
CÃES SEM PLUMAS: OS DESPOSSUÍDOS NA ARTE CONTEMPORÂNEA BRASILEIRA*
}

Moacir dos Anjos Fundação Joaquim Nabuco, Recife, PE - Brasil.<moacir_anjos@uol.com.br>

http://dx.doi.org/10.1590/ 0102-6445163-175/96

Dificil é saber / se aquele homem / já não está / mais aquém do homem [...] (João Cabral de Melo Neto, "O cão sem plumas")

Este texto introduz questões julgadas como pertinentes à investigação dos modos como a arte brasileira contemporânea representa ou deixa de representar situações de despossessão a que parcelas da população brasileira são historicamente submetidas. E embora o termo despossessão possa abrigar sentidos variados (e não necessariamente conflitantes), aqui se quer destacar um deles somente: seu poder de descrever situações em que pessoas são destituídas, por poderes normativos e normalizadores, dos meios que as poderiam proteger de uma situação de vulnerabilidade material e psíquica. Situações que

\footnotetext{
* Versões preliminares deste texto foram apresentadas nos ciclos de palestras Aberto para Balanço: Arte e Cultura no Brasil dos últimos 20 anos, realizado no Centro Universitário Maria Antonia (USP), São Paulo, em setembro de 2013, e Memória, Arte e Educação em Direitos Humanos, realizado no Instituto de Estudos Avançados da Universidade de São Paulo, em novembro de 2014. O autor agradece aos participantes dos dois eventos por seus comentários e sugestões, sem implicá-los no conteúdo aqui publicado.
} 
implicam a existência de desigualdades no acesso aos mecanismos que defendem vidas de violências econômicas e afetivas (ou as expõem a tais violências), bem como da regulação biopolítica dos corpos. São duas, ademais, as circunstâncias que enquadram sua escrita. Primeiramente, de ser relativamente pequeno o interesse que a questão desperta entre artistas brasileiros, notadamente quando se compara esse pouco interesse com a adesão ao tema observada em países com índices de exclusão semelhantes, notadamente na América Latina. Em segundo lugar, de a gravidade dessas situações de exclusão não ter sido atenuada pelas transformações econômicas e sociais ocorridas no Brasil após o ano 2000, as quais levaram à melhoria dos padrões de vida de tantos brasileiros. Transformações que ancoraram, inclusive, o dinamismo do mercado, observado no período, para a arte contemporânea no país, bem como suas articulações com mecanismos de valoração patrimonial da produção artística no exterior.

164 É fato que o Brasil passou, entre meados da década de 1990 e início da década de 2010, por uma série de grandes transformações socioeconômicas. Mudanças que, conforme atestam os dados consagrados para medi-las, estiveram associadas ao aumento do Produto Interno Bruto (total e per capita), à redução drástica da inflação, à diminuição do desemprego (ver Tabela 1) e, por fim, à desconcentração de renda, ainda que pouco se tenha alterado a relação entre o que é apropriado daquele produto pelo $1 \%$ mais rico do país e o que cabe dele ao restante da população, evidenciando os abismos que continuam apartando segmentos sociais no Brasil ${ }^{1}$. Também

\footnotetext{
${ }^{1}$ O comportamento do coeficiente de Gini - principal medidor da concentração de renda em um país - demonstra acentuada diminuição ao longo do período no Brasil, passando de 0,567 em 1997 para 0,507 em 2012 (quanto mais próximo de zero for o coeficiente, mais igualitária é a repartição da renda no país; contrariamente, quanto mais próximo ele for da unidade, mais concentrada é a renda). A parcela da renda nacional apropriada pelo $1 \%$ mais rico do país não diminuiu, contudo, com a mesma intensidade, passando de 13,8\%, em 1998, para 12,5\%, em 2012 (Fonte: Pesquisa Nacional por Amostra de Domicílios - Pnad/IBGE).
} 
no campo da cidadania e da proteção social, esse foi um período de notáveis avanços, quer na consagração em leis de direitos antes negados pelo Estado, quer na criação de um fundo social (ainda carente de institucionalização) que visa dotar as famílias mais pobres de uma renda mínima para custeio de gastos básicos à sobrevivência. Esse foi, por fim, o momento em que o protagonismo internacional do país cresceu e consolidou-se em termos econômicos, políticos e simbólicos. Ao lado de Rússia, Índia, China e África do Sul, o Brasil passou a compor um bloco de países (os chamados BRICs) que progressivamente ocupam espaços estratégicos em um cenário de rápidas e profundas transformações geopolíticas.

\begin{tabular}{|c|c|c|c|c|c|c|}
\hline & & Indicador & macroe & nômicos & & \\
\hline & & & & iável & & \\
\hline & 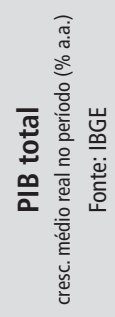 & 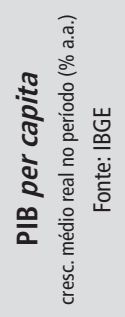 & 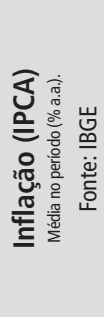 & 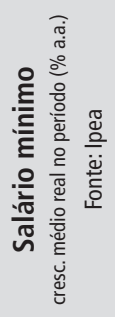 & 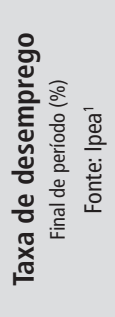 & 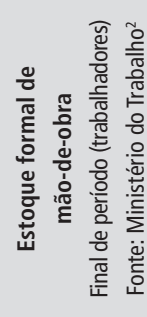 \\
\hline 1983-1992 & 2,1 & 0,1 & 723,0 & $-8,7$ & 7,2 & 18.471 .874 \\
\hline 1993-2002 & 2,9 & 1,3 & 346,8 & 5,6 & 9,9 & 21.953 .360 \\
\hline 2003-2012 & 3,6 & 2,6 & 5,9 & 5,9 & 7,0 & 37.639 .286 \\
\hline
\end{tabular}

(1) Taxas nos anos de 1992, 2002 e 2012. Percentual das pessoas que procuraram, mas não encontraram ocupação profissional remunerada entre todas aquelas consideradas ativas no mercado de trabalho, grupo que inclui todas as pessoas com 10 anos ou mais de idade que estavam procurando ocupação ou trabalhando na semana de referência da Pesquisa Nacional por Amostra de Domicílios (Pnad/ IBGE). Elaboração: Disoc/Ipea a partir dos microdados da Pnad.

(2) Estoque total de trabalhadores formais (RAIS, exclui militares e estatutários) nos anos de 1995, 2002 e 2012. Ano de 2012 estimado a partir dos dados do Cadastro Geral de Empregados e Desempregados do Ministério do Trabalho.

Fonte: LCA Consultores. 
Esses foram também anos de extremo dinamismo para o campo das artes visuais no país, e, em particular, para a chamada arte contemporânea. Beneficiados por lei de isenção fiscal para patrocínio de ações culturais implantadas em nível federal - princípio posteriormente adotado em diversos estados e municípios -, muitos museus de arte foram reformados ou mesmo construídos, passando a receber exposições itinerantes de grande porte (produzidas no Brasil ou no exterior), também financiadas por tais instrumentos de abate fiscal (Anjos, 2006). Ainda que em menor medida, esses mecanismos foram igualmente utilizados para restaurar ou adquirir acervos públicos. A face mais visível dessas mudanças é, contudo, o intenso crescimento do mercado de arte contemporânea, fora e dentro do país. Por um lado, houve crescente participação de galerias brasileiras em feiras de arte internacionais, além da negociação de obras de artistas locais em casas de leilões no exterior por 166 valores nunca antes sequer aproximados ${ }^{2}$. Por outro lado, a criação e rápida expansão de duas feiras internacionais de arte no Brasil (uma em São Paulo, outra no Rio de Janeiro) expressam o interesse (sobretudo patrimonial) que as artes visuais cada vez mais despertam no país (Fialho, 2013).

Em todas essas instâncias - institucionais e de mercado, públicas e privadas -, a arte brasileira contemporânea é celebrada por sua originalidade e por supostamente espelhar, no campo do sensível, a superação de graves entraves ao crescimento econômico do Brasil e a afirmação, por vezes antes somente ensaiada, da suposta relevância global do país. Quase como se a promessa de emancipação contida na arte e arquitetura brasileiras, feitas na década de 1950 e no início da seguinte

2 Essa internacionalização tem sido dinamizada através do projeto Latitude Platform for Brazilian Art Galleries Abroad, fruto de parceria entre a Apex-Brasil (Agência Brasileira de Promoção de Exportações e Investimentos), um órgão do governo federal, e a ABACT (Associação Brasileira de Arte Contemporânea), formada por galerias de arte privadas. 
(também sugerida, em equivalente musical, na bossa-nova), finalmente encontrasse condições materiais para se efetivar.

Os fatos do cotidiano vêm o tempo todo lembrar, todavia, dos limites dessa dinâmica positiva observada, com nitidez, no último decênio e meio no país. Eles mostram que, a despeito do movimento de inclusão observado, existem comunidades simplesmente excluídas dos ganhos que as transformações modernizadoras empreendidas pelo Brasil nesses anos trouxeram a muitos, seja no campo tecnológico, no da gestão macroeconômica e no da cidadania e da proteção social. Comunidades que vivem à margem de quase tudo que outros já alcançaram no país, e para as quais somente existem interdições. São fatos que atestam a permanência de grupos diversos de pessoas cujas vidas são marcadas por lacuna e por ausência. E é nesse contexto que importa investigar em que medida a arte contemporânea brasileira representa essas situações de despossessão que acometem parcelas da população do país.

Entre esses grupos está, por exemplo, a maior parte dos índios que vivem no Brasil, acossados por doenças e pela cobiça sobre as terras a que pertencem, de que os conflitos envolvendo os Guarani Kaiowá no Mato Grosso do Sul são evidência grave e recente, bem como a longa luta travada pelos Yanomami no norte do país pela manutenção de seu território supostamente garantido em lei, entre tantas outras disputas envolvendo diversas etnias. Fazem parte dessas populações desassistidas também os loucos e presidiários que apodrecem em um sistema curativo e prisional falido, assim como as crianças e adolescentes que moram nas ruas e gastam o pouco tempo de vida que ainda vão ter entre esmolas, delitos e o inevitável enlace com a dependência química. São também excluídos dos ganhos socioeconômicos obtidos por parcela significativa da população brasileira de anos recentes aqueles que, diante da violência desregulada no campo ou da voracidade especulativa sobre 
o espaço urbano, terminam sendo retirados à força de seus lugares de vida e destituídos dos meios de sobrevivência. Ou os tantos de quem o Estado suspende seus direitos mais básicos mesmo sob um regime democrático (evocando atos da polícia política do passado de exceção do país), perseguidos por serem negros, homossexuais ou apenas por serem pobres. Assim como são despossuídos os estrangeiros que, atraídos pela expectativa criada de vida melhor para os que moram no Brasil, terminam aviltados em suas prerrogativas mais simples, como é o caso de tantos bolivianos que vivem São Paulo ou de haitianos que migraram para o Acre fugindo do esfacelamento da vida comum em seu país. $\mathrm{O}$ que une todas essas pessoas é o fato de elas não serem contabilizadas no cálculo produtivista que rege e mede o avanço econômico do Brasil. No pior dos casos, como ocorre com tantas populações indígenas, essa despossessão é não somente absoluta, mas muitas vezes funcional e necessária 168 ao modelo de desenvolvimento adotado no país.

O título deste ensaio é tomado emprestado de verso do poema "O cão sem plumas", de João Cabral de Melo Neto, originalmente publicado em 1950. Adoção que sugere uma proximidade entre alguns artistas visuais brasileiros e o poeta pernambucano, já explorada na exposição Cães sem Plumas $^{3}$. Não por aqueles terem criado obras marcadas pela escrita angular do escritor, mas por partilharem com ele um desassossego diante do que testemunham nos lugares onde transitam ou moram, e que o texto cabralino fixa de modo singular. A poesia de João Cabral de Melo Neto é magra, não cabendo nela excessos retóricos. É construída por

\footnotetext{
3 A exposição Cães sem Plumas foi realizada, com curadoria do autor deste texto, no Museu de Arte Moderna Aloisio Magalhães (Mamam), no Recife, entre 23 de abril e 6 de julho de 2014. A mostra teve uma edição anterior e mais compacta - intitulada Cães sem Plumas [prólogo] - realizada em 2013 na Galeria Nara Roesler, em São Paulo, como parte do projeto Roesler Hotel. Ambas as versões da exposição, bem como o presente ensaio, resultam de pesquisa de mesmo nome desenvolvida na Fundação Joaquim Nabuco.
} 
desbaste cuidadoso dos muitos significados possíveis que cada palavra carrega, dotando-as de secura que renova a linguagem. Por subtrair do texto criado tudo que é redundante ou sobra, foi chamada, apropriadamente, de "poesia do menos". Tal operação de abate não retira das palavras que usa, contudo, seu poder de ressoar, com agudeza e detalhe, ideias e coisas que fazem o mundo ser como é. Ao contrário, a magreza de sua poesia ecoa, comenta e refaz, em termos próprios, um espaço social marcado por carência e falta (Secchin, 1985). Talvez em nenhum outro poema de João Cabral de Melo Neto essa relação entre as palavras e a vida nelas contida seja mais precisa e próxima do que em "O cão sem plumas", texto em que o autor descreve, com o pulso inventivo da linguagem que usa, o Recife ribeirinho de 1950, atravessado pelo rio Capibaribe. Na visão crítica e concisa do poeta, esse era ambiente que tinha algo "da estagnação / do hospital, da penitenciária, dos asilos, / da vida suja e abafada / (de roupa suja e abafada) / por onde se veio arrastando" o rio. Ao longo do poema, o curso do Capibaribe e o curso das vidas dos que vivem próximos às suas águas e lamas se tornam, no encadeamento de palavras, progressivamente indistintos, fazendo da descrição de uma paisagem de penúria a narração simultânea de ruínas pessoais daqueles que a habitam. $\mathrm{O}$ rio e os moradores de tal lugar seriam ambos "cães sem plumas", expressão que parece designar, em forma de radical paradoxo, situações de destituição absoluta. Um “cão sem plumas”, escreve João Cabral de Melo Neto, "é quando uma árvore sem voz. / É quando de um pássaro / suas raízes no ar. / É quando a alguma coisa / roem tão fundo / até o que não tem" (Melo Neto, 1950).

Evoca-se esse poema aqui, portanto, para reclamar o emprego da ideia do "cão sem plumas" como metáfora que identifica, na produção de um conjunto de artistas visuais, a representação de grupos de pessoas que, por sua condição 
de despossuídos, estão do lado de lá daquilo que o sociólogo português Boaventura de Souza Santos (2006) chama de "linha abissal", que é aquela linha invisível que "separa o domínio do direito do domínio do não direito". Ou seja, são pessoas e grupos que estão além da fronteira de visibilidade social de suas vidas; estão no lugar onde inexiste distinção entre o legal e o ilegal ou entre a verdade e a mentira, ou mesmo entre a vida e a morte. Para além da linha abissal, a humanidade é subtraída. Lá, a exclusão é radical, pois não há como ser incluído no contexto em que essa divisão se afirma. Além da linha abissal, fica o "gueto" (Meireles, 2000) onde vivem os cães sem plumas, ou as "zonas de abandono social" (Biehl, 2005) a que são destinadas as pessoas que, por um ou outro motivo, são incapazes de ter uma vida economicamente ativa.

Artistas que, de forma continuada ou pontual em suas trajetórias, criam narrativas nas quais inscrevem danos de 170 várias ordens infligidos a parcelas específicas da população do país, quase sempre ausentes de sua paisagem simbólica. Sem querer ser exaustivo, podem-se citar, entre esses artistas visuais, aqueles incluídos na exposição Cães sem Plumas: Antonio Dias, Armando Queiróz, Berna Reale, Carlos Vergara, Cildo Meireles, Claudia Andujar, Eduardo Coutinho, Gil Vicente, João Castilho, Jonathas de Andrade, José Rufino, Marcos Chaves, Maria Thereza Alves, Matheus Rocha Pitta, Paula Trope, Paulo Bruscky, Paulo Nazaré, Regina Parra, Rosângela Rennó, Thiago Martins de Mello e Virgínia de Medeiros. É certo que há vários danos que não são computados em suas obras, assim como diversos outros artistas que não participaram da mostra também lidam com questões que mobilizam os mencionados, como é o caso, em meio a mais alguns, de Artur Barrio, Clara Ianni, Maurício Dias \& Walter Riedweg, Miguel Rio Branco e Rosana Palazyan. Não há, porém, qualquer pretensão de completude no que é dito aqui. Antes e longe de exaurir a amplitude do tema, 
o que se busca é tornar minimamente visíveis assuntos ainda pouco confrontados no campo da arte contemporânea brasileira, como se não valessem o bastante para isso ou, no limite, sequer existissem. O grau de despossessão que marca os "cães sem plumas" representados nos trabalhos desses e de outros artistas é índice inequívoco de que, a despeito de ter mudado muito e beneficiado tantos os que antes pouco tinham, o Brasil permanece desigual e excludente.

Mas propor uma narrativa mais inclusiva implica reconhecer que há uma forma hegemônica de a arte contemporânea representar o país, à qual se sugere referir como representação partida. Partida, em primeiro lugar, por ser, como qualquer forma de representação, uma equivalência da realidade e, como tal, não se confundir com a realidade representada. Nesse sentido de incompletude ou de desajuste do equivalente com a realidade, toda representação é de algum modo partida; há sempre algo que nela falta ou que nela é falha (Rancière, 2012). A expressão representação partida também remete, todavia, a outro e mais específico sentido: ela sugere que aquilo que falta ou que não cabe nessa representação são justamente os indícios das exclusões e das interdições que marcam, e em alguma medida definem, a dinâmica da sociedade brasileira. Na representação partida não cabem os "cães sem plumas".

A representação partida é, portanto, um conjunto de equivalências sensíveis da realidade brasileira (algo que, por definição, já embute ausências ou faltas) que não levam em conta, especificamente, o caráter fraturado do país, ou seja, uma representação cujas ausências ou faltas coincidem, justamente, com as ausências e faltas daqueles que, embora seres viventes e moradores do Brasil, não são contados como parcelas da sociedade brasileira. E é importante anotar que essa representação partida não é, em princípio, inadequada como representação do contexto ao qual ela se refere e no qual ela se insere. Em verdade, ela termina 
por produzir equivalentes sensíveis de uma sociedade que aliena, de si mesma, tudo que é incômodo, que causa atrito, que provoca disputa, que gera ruído ou que é sujeira. A ausência, nessa representação partida, daquilo que é também escamoteado ou esquecido na sociedade da qual ela é equivalente sensível a torna uma representação perversamente adequada da realidade brasileira.

Mesmo que indiretamente, e sem intenção declarada de quem a constrói, a produção em artes visuais que formula essa representação partida corrobora e reforça uma visão de país que é hoje hegemônica interna e externamente. A visão de um país que estaria conciliado com ele mesmo, com o comum que foi construído ao longo das últimas décadas, com a partilha desse comum em determinados quinhões e com sua distribuição para determinadas partes (Rancière, 2005). Uma visão de país em que os "cães sem plumas" não possuem imagem e não têm voz. Em que sim-

172 plesmente não são contados, a despeito de qualquer juízo de valor estético sobre os trabalhos que produzem tal forma de representação.

Há, contudo, um tipo de inadequação associado a essa representação partida. Inadequação em relação à temporalidade a que essa produção artística reivindica pertencer; a reivindicação de contemporaneidade dessa representação. E, para entender essa inadequação, é preciso destacar o sentido que Giorgio Agamben dá ao contemporâneo. Não como adesão perfeita ou como fidelidade a determinado tempo, pois essa aderência e essa fidelidade não permitem que se veja de fato o que determina e define esse tempo. Uma perfeita aderência ao tempo em que se vive significa, nesse sentido preciso, uma celebração acrítica daquilo que é atual. Para o filósofo, ser contemporâneo de um tempo significa ser, ao contrário, anacrônico, deslocado do tempo em que se vive, ver esse tempo a contrapelo, olhá-lo com desconfiança, mostrar-se inadequado às suas pretensões e às suas exigências. 
Ser contemporâneo, nesse sentido, é estar próximo de seu tempo e, simultaneamente, também tomar distância dele (Agamben, 2009). Nesse contexto, é possível dizer que, no limite, a representação partida, tal como aqui definida, não é de fato contemporânea. E não o é porque não interpela criticamente a ordem hegemônica que regula e controla o país. Não é contemporânea porque não é capaz de criar equivalentes sensíveis para as sombras do país.

Em contraposição a essa representação partida é possível argumentar que existe, nas obras de artistas em atividade no país e em contraponto extremo à representação partida, outra forma de representação do Brasil, à qual se pode chamar de representação das sobras. Ao contrário da representação partida, a representação das sobras seria aquela que nomeia danos que são infligidos a segmentos da população do país; que aponta e individualiza os excluídos da dinâmica social que envolve e abriga a maior parte dos habitantes do Brasil; que desfaz ideias rasas de inclusão irrestrita. Representação que reclama, portanto, a condição de parte para aquilo que é considerado sobra; que cria equivalências simbólicas para o que no mais das vezes é representado, paradoxalmente, somente como ausência e falta; que reclama a condição de alguém para quem é ninguém. Os indivíduos e grupos assim representados são justamente aqueles aqui chamados de "cães sem plumas". No sentido dado ao termo por Giorgio Agamben, a representação das sobras seria de fato contemporânea.

É importante destacar que a representação das sobras não é, por necessidade, mera ilustração de uma situação de exclusão para além da linha abissal de que fala Boaventura de Souza Santos (2006), lá onde vivem os “cães sem plumas". Na representação das sobras, tal como é sugerida aqui, existe uma tensão permanente entre visibilidade e opacidade de danos, entre entender e não entender suas causas. Opacidade que é, inclusive, índice de respeito diante da diferença da vida do outro 
que, ao contrário daquele que o representa, está em situação de exclusão radical da vida social partilhada (Glissant, 2007). Igualmente importante é deixar claro que a representação das sobras não se confunde com a criação artística dos excluídos, nem mesmo com a sua autorrepresentação no campo do sensível. Na representação das sobras está inscrita, ao contrário, uma relação de confronto com o outro, de aproximação agonística com a alteridade. Está implícita a tentativa de um entendimento que sempre esbarra numa impossibilidade, mas que ainda assim se faz urgente e necessária. É expressão de uma política da arte que busca de algum modo refazer a partilha das partes num dado corpo social. A representação das sobras possui, além do já dito, dois traços adicionais. Primeiro, reconhece que persiste e se reproduz, no Brasil e em outros lugares, um tipo de vida na qual gradualmente se desmancha o que de humano pode haver nela. Em segundo lugar, demonstra saber ser impossível dissociar essa situação de priva-

174 ção extrema da indiferença que ela desperta naqueles que têm a sua humanidade preservada, ou seja, da indiferença daqueles que já são considerados partes e que têm o seu quinhão no comum partilhado. A representação das sobras se ocupa daquilo que João Cabral chamava, em seu poema, de "vidas roídas”. Se ocupa, portanto, em criar equivalências sensíveis da realidade que tornem visíveis os nexos entres gentes, espaços e fatos que promovem a despossessão radical dessas vidas.

\section{Moacir dos Anjos}

é pesquisador e curador da Fundação Joaquim Nabuco (Recife, Pernambuco).

\section{Bibliografia}

AGAMBEN, G. 2009. "O que é o contemporâneo?". In: O quééo contemporâneo? e outros ensaios. Chapecó, SC: Argos.

ANJOS, M. dos. 2006. "Dinamismo e crise dos museus de arte no Brasil". Revista Eletrônica Z, n. 1. 
BIEHL, J. 2005. Vita. Life in a zone of social abandonment. Berkeley/Los Angeles: University of California Press.

FIALHO, A. L. (2013). Pesquisa setorial. O mercado de arte contemporânea no Brasil. 2. ed. São Paulo: Latitudes.

GLISSANT, E. 2007. "For opacity". In: Poetics of relation. Michigan: University of Michigan Press.

MEIRELES, C. 2000. "Notas”. In: CAMERON, D., HERKENHOFF, P.; MOSQUERA, G. (orgs.). Cildo Meireles. São Paulo: Cosac \& Naify. MELO Neto, João Cabral de. 1950. O cão sem plumas. Barcelona: O livro inconsútil.

1984. O cão sem plumas. 2. ed. Rio de Janeiro: Nova Fronteira (fotografias de Maureen Bisilliat).

RANCIÈRE, J. 2005. A partilha do sensível. Estética e política. São Paulo: $\mathrm{EXO} /$ Editora 34. . 2012. "Paradoxos da arte política". In: O espectador emancipado. São Paulo: WMF Martins Fontes.

SECCHIN, A. C. 1985. João Cabral: a poesia do menos. São Paulo/Brasília: Duas Cidades/INL (Fundação Nacional Pró-Memória).

SOUSA SANTOS, B. de. 2006. "Para além do pensamento abissal: das linhas globais a uma ecologia de saberes”. In: A gramática do tempo: para uma nova cultura política. São Paulo: Cortez. 


\section{CÃES SEM PLUMAS: OS DESPOSSUÍDOS NA ARTE CONTEMPORÂNEA BRASILEIRA}

MOACIR DOS ANJOS

Resumo: Tomando um verso do poeta João Cabral de Melo Neto como metáfora para a situação de despossessão em que vivem parcelas da população brasileira, este artigo aponta duas maneiras em que tais grupos sociais são representados pela produção contemporânea em artes visuais no Brasil. A primeira é a representação partida, que os ignora e assim os exclui do universo sensível partilhado socialmente. A segunda é a representação das sobras, que se ocupa em criar equivalências sensíveis da realidade brasileira que tornam visíveis os nexos entres gentes, espaços e fatos que promovem a despossessão radical de vidas.

Palavras-chave: Arte; Representação; Despossessão.

\section{DOGS WITHOUT FEATHERS: REPRESENTATION OF THE DISPOS- SESSED IN BRAZILIAN CONTEMPORARY ART}

Abstract: Taking a verse from the poet João Cabral de Melo Neto as a metaphor for the situation of dispossession faced by portions of the Brazilian population, the text points out two ways in which these social groups are represented by the contemporary production in visual arts in Brazil. The first one is the partial representation, which ignores and thus excludes them from the socially shared realm of the sensible. The second one is the representation of the remains, which creates sensible equivalences of Brazilian reality that make visible the links between peoples, places and events that promote the radical dispossession of lives.

Keywords: Art; Representation; Dispossession.

Recebido: 03/08/2015 Aprovado: 17/08/2015 